\title{
Comparison of the Effects of Damage to the Perirhinal and Parahippocampal Cortex on Transverse Patterning and Location Memory in Rhesus Macaques
}

\author{
Maria C. Alvarado and Jocelyne Bachevalier \\ Department of Neurobiology and Anatomy, University of Texas Health Science Center at Houston, Houston, Texas 77030
}

\begin{abstract}
Monkeys with damage to the parahippocampal (TH/TF) or perirhinal ( $\mathrm{PRh}$ ) cortex were tested on two sets of the transverse patterning (TP) problem $(\mathrm{A}+/ \mathrm{B}-, \mathrm{B}+/ \mathrm{C}-, \mathrm{C}+/ \mathrm{A}-$ and $\mathrm{D}+/ \mathrm{E}-, \mathrm{E}+/ \mathrm{F}-, \mathrm{F}+/ \mathrm{D}-)$ and delayed nonmatching-to-location paradigm (DNML), with delays ranging from 10 to $600 \mathrm{~s}$. Damage to either area impaired acquisition and performance of TP but not of linear discriminations (e.g., $\mathrm{A}>\mathrm{B}>\mathrm{C}>\mathrm{X}$ ). Damage to areas TH/TF impaired performance of the DNML at all delays but only affected memory for objects at the longest delay, as measured by a delayed nonmatching-to-sample task (DNMS) (Nemanic et al., 2004). Damage to the PRh impaired performance of the DNMS but not of the DNML. The results present a dissociation in object and place memory for these two cortical regions and suggest a role for each in the cortical circuitry supporting configural/relational memory.
\end{abstract}

Key words: configural memory; relational memory; discrimination learning; spatial memory; recognition memory; temporal lobe

\section{Introduction}

Recent studies have begun to investigate the specific contribution that the hippocampus and the adjacent parahippocampal cortices [including the entorhinal cortex, perirhinal cortex $(\mathrm{PRh})$, and areas $\mathrm{TH} / \mathrm{TF}$ ] make to memory processes (Lavenex and Amaral, 2000; Murray et al., 2000; Suzuki and Eichenbaum, 2000). For object recognition, emerging views suggest that the parahippocampal cortical areas may mediate familiarity/novelty judgements of individual stimuli (Brown and Aggleton, 2001; Yonelinas, 2002), whereas the hippocampus is needed to acquire, store, and recollect inter-item relationships and their context (Eichenbaum et al., 1989; Squire et al., 1989; Sutherland and Rudy, 1989; Mishkin et al., 1998; O'Reilly and Rudy, 2001). However, other data do not support this view (Manns and Squire, 1999; Wood et al., 1999; Stark et al., 2002).

Likewise, although the well established role of the hippocampus in rodent spatial memory has been replicated in both monkeys (Parkinson et al., 1988; Gaffan and Harrison, 1989; Angeli et al., 1993; Murray et al., 1998; Beason-Held et al., 1999; Hampton et al., 2004; Alvarado and Bachevalier, 2005) and humans (Maguire et al., 1998; Iaria et al., 2003), that of parahippocam-

Received 0ct. 29, 2004; revised Dec. 7, 2004; accepted Dec. 31, 2004.

This work was supported in part by National Institute of Mental Health (NIMH) Grant MH-58846 and National Institute of Child Health and Human Development Grant HD-35471 to J.B. and by National Research Service Award Grant F32 MH-10929 to M.C.A. We thank the veterinary staff at the Laboratory of Neuropsychology at NIMH (Bethesda, MD) and the (enter for Laboratory Animal Management and (are at the University of Texas for expertise and valuable help in the preoperative and postoperative care of the monkeys. We thank Leah Swann, Amanda Thomas, and Dodie Baccigalopi for assistance in behavioral testing and Fernando Latunio for histological preparation of the brains. We gratefully acknowledge Dr. Mortimer Mishkin for his continuing collaboration.

Correspondence should be addressed to Dr. Maria C. Alvarado, Yerkes National Primate Center, Emory University, 954 Gatewood Road Northeast, Atlanta, GA 30329. E-mail: malvara@emory.edu.

J. Bachevalier's present address: Yerkes National Primate Center, Emory University, Atlanta, GA 30329

DOI:10.1523/JNEUROSCI.4457-04.2005

Copyright $\odot 2005$ Society for Neuroscience $\quad$ 0270-6474/05/251599-11\$15.00/0 pal cortical areas is still controversial. Areas TH/TF contribute to spatial memory in monkeys and humans (Bohbot et al., 1998; Ploner et al., 2000; Kohler et al., 2002; Nemanic and Bachevalier, 2002; Málková and Mishkin, 2003), although similar evidence in rodents is task dependent (Liu and Bilkey, 2002; Burwell et al., 2004; Jarrard et al., 2004; Winters et al., 2004). Furthermore, perirhinal damage impairs performance on some spatial memory tasks (Wiig and Bilkey, 1994; Nagahara et al., 1995; Otto et al., 1997; Liu and Bilkey, 1998a,b) but not others (Gaffan, 1994; Ennaceur et al., 1996; Aggleton et al., 1997; Wiig and Burwell, 1998; Bussey et al., 1999; Winters et al., 2004), and perirhinal neurons do not change their pattern of activation during spatial memory tasks (Burwell et al., 1998; Aggleton et al., 2000; Vann et al., 2000).

Finally, with respect to configural and/or relational memory (Rudy and Sutherland, 1995; Eichenbaum, 2001; O’Reilly and Rudy, 2001), hippocampal damage impairs nonspatial relational memory tasks (Ridley et al., 1995; Clark et al., 2002), including the transverse patterning problem in rodents, monkeys, and humans (Alvarado and Rudy, 1995a,b; Dusek and Eichenbaum, 1998; Rickard and Grafman, 1998; Reed and Squire, 1999; RondiReig et al., 2001; Alvarado et al., 2002; Alvarado and Bachevalier, 2005), and performance on relational memory tasks is associated with hippocampal activation in humans (Davachi and Wagner, 2002; Driscoll et al., 2003; Hanlon et al., 2003; Astur and Constable, 2004; Heckers et al., 2004; Preston et al., 2004). However, performance on configural tasks is also impaired by perirhinal and/or TH/TF damage (Buckley and Gaffan, 1998; Dusek and Eichenbaum, 1998; Eacott et al., 2001; Bucci et al., 2002; Bussey et al., 2002; Moran and Dalrymple-Alford, 2003), suggesting that these cortical areas may, likewise, contribute to relational memory.

Given these conflicting results, the degree to which parahippocampal cortical areas contribute to memory processes, either 
Table 1. Number of subjects participating in each task or analysis

\begin{tabular}{|c|c|c|c|c|c|}
\hline \multirow[b]{2}{*}{ Group } & \multicolumn{3}{|c|}{ Transverse patterning } & \multicolumn{2}{|c|}{ Recognition memor) } \\
\hline & Session-blocked & Phase-blocked & Performance & DNMS & DNML \\
\hline $\mathrm{N}$ & $4^{a}$ & $3^{b}$ & $7^{b}$ & $7^{c}$ & 7 \\
\hline PRh & - & 4 & 4 & $3^{c}$ & 3 \\
\hline $\mathrm{TH} / \mathrm{TF}$ & - & 3 & 3 & $3^{c}$ & 3 \\
\hline
\end{tabular}

${ }^{a}$ Data published in the study by Alvarado et al. (2002).

${ }^{b}$ Data published in the study by Alvarado and Bachevalier (2005).

'Data published in the study by Nemanic et al. (2004).

Table 2. Task-training history

\begin{tabular}{lllllll}
\hline Subjects & $\mathrm{CD}^{a}$ & $\mathrm{TP}$ & $\mathrm{VPC}^{a}$ & s-DNMS & $\mathrm{d}^{2}$ DNMS $^{a}$ & DNML $^{2}$ \\
\hline N 1-3 & - & 1 & 2 & 3 & 4 & 5 \\
N 4-7 & 2 & 4 & 3 & 1 & - & 5 \\
TH/TF 1-3 & - & 1 & 2 & 3 & 4 & 5 \\
PRh 2 & - & 1 & 2 & 3 & 4 & - \\
PRh 3-5 & - & 1 & 2 & 3 & 4 & 5
\end{tabular}

The numbers refer to the order $(1,2,3$, etc.) in which subjects were trained on each task. $C D$, Concurrent discrimination; TP, transverse patterning; s-DNMS, DNMS, standard version (Nemanic et al., 2004); d-DNMS, DNMS with distracters (Nemanic et al., 2004).

${ }^{a}$ Training on tasks not discussed in the present study.

independently or in concert with the hippocampus, remains to be determined. To this end, the effects of damage to either areas $\mathrm{TH} / \mathrm{TF}$ or the PRh on transverse patterning and delayed nonmatching-to-location (DNML) were compared with those recently obtained after neurotoxic damage to the hippocampus (Alvarado and Bachevalier, 2005). A preliminary report of this work was published previously (Alvarado and Bachevalier, 2003).

\section{Materials and Methods \\ Subjects}

The subjects were 14 rhesus macaques (Macaca mulatta), of both sexes, 6-12 years old at the time of surgery. Four monkeys (one male and three females) received aspiration lesions of the PRh, and three monkeys (two males and one female) received aspiration lesions of cortical areas $\mathrm{TH}$ and TF on the parahippocampal gyrus. Data from these two groups were compared with those of seven (five males and two females) unoperated controls $(\mathrm{N})$. The performance of these unoperated controls on the transverse patterning and DNML have been published previously (Alvarado et al., 2002; Alvarado and Bachevalier, 2005). Behavioral testing history and order of task presentation for each animal are summarized in Tables 1 and 2, respectively.

Animals were housed individually and maintained on a diet of Purina Monkey Chow, supplemented with fresh fruit and multivitamins. During behavioral testing, the food ration was given once daily, immediately after training, and the rations were adjusted individually to allow for rapid responding during test sessions, while maintaining the animal at $\geq 90 \%$ of their free-feeding weight. Water was always available. The study was approved by the Institutional Animal Care and Use Committee of the University of Texas Health Science Center at Houston.

After completion of testing on transverse patterning and before testing on DNML, all control subjects, the three subjects in group TH/TF, and three subjects from group PRh were tested on the visual paired comparison task (VPC) and a delayed nonmatching-to-sample task (DNMS) with pseudotrial-unique objects (Nemanic et al., 2004). Case PRh-2 was also tested on VPC and DNMS, but not on DNML, and so was not included in statistical analyses in which performance on DNML was used; case PRh-1, from the study by Nemanic et al. (2004), was not part of the present study.

\section{Surgery}

Surgical procedures and preoperative and postoperative care were described in detail previously (Nemanic et al., 2004). Briefly, on the day of surgery, the monkey was sedated $(10 \mathrm{mg} / \mathrm{kg}$ ketamine hydrochloride) and placed into a head holder. Surgical anesthesia was induced and main- tained with isoflurane gas ( $1-2 \%, v / v$, to effect), and heart rate, respiration rate, blood pressure, body temperature, and expired $\mathrm{CO}_{2}$ were monitored throughout the surgery, which was performed under aseptic conditions. All monkeys received preoperative and postoperative treatment consisting of dexamethasone sodium phosphate $(0.4 \mathrm{mg} / \mathrm{kg}, \mathrm{i} . \mathrm{m}$.) and cefazolin $(25 \mathrm{mg} / \mathrm{kg}$, i.m.) $1 \mathrm{~d}$ before surgery and for 1 week after surgery to reduce swelling and to prevent infection, respectively. They also received acetaminophen for $7 \mathrm{~d}$ after surgery for relief of pain. The monkeys were allowed to recover for 6 months before behavioral testing began. Surgeries for case PRh-2, case PRh-3, and the three cases in group $\mathrm{TH} / \mathrm{TF}$ were conducted at the Laboratory of Neuropsychology at the National Institute of Mental Health (Bethesda, MD), and the animals were then transferred to the Department of Neurobiology and Anatomy at the University of Texas Health Science Center (Houston, TX) for behavioral testing. Surgeries for cases PRh- 4 and PRh-5 were conducted at the University of Texas Health Science Center.

TH/TF lesions. The lesions were intended to include both areas $\mathrm{TH}$ and TF (von Bonin and Bailey, 1947), and delineation of the intended TH/TF lesions is given in Figure 1. A one-stage bilateral aspiration was performed using a supralabyrinthine approach. A bone flap was made over the ventrolateral surface of the temporal lobe, and the dura was cut in a crescent over the temporal lobes. The borders of the lesion extended to the lip of the medial bank of the occipitotemporal sulcus laterally, to the brain stem medially, and to the posterior tip of the rhinal sulcus rostrally. Caudally, the posterior middle temporal sulcus was identified, and its midpoint was localized. A virtual line was drawn from this midpoint until it intersected with the occipitotemporal sulcus. The intersection was marked with the cautery and used as the most posterior extent of the TH/TF lesions.

PRh lesions. Bilateral aspirations of the PRh were performed in one stage, using procedures developed by Bachevalier and colleagues (Meunier et al., 1993). The lesion was intended to include Brodmann areas 35 and 36 (see Fig. 2). The zygomatic arch and the bone over the ventrolateral surface of the frontotemporal junction were removed. For the rostral portion of the lesion, the dura was cut in a crescent over the frontal and temporal lobes, and the frontal lobe above the orbit was elevated slightly to expose the medial temporal pole. The pia matter on the lateral lip of the rhinal sulcus was cauterized as far posterior as the rhinal sulcus could be seen, after which the lateral bank of the rhinal sulcus as well as a $2 \mathrm{~mm}$ strip of cortical tissue lateral to it was aspirated using a small gauge sucker. To access the caudal portion of the PRh, the head-holder was rotated until the monkey's head was tilted at an angle of $120^{\circ}$ from the upright position, and a second incision was made in the dura over the lateral temporal lobe. The base of the temporal lobe was reflected to visualize the posterior end of the rostral removal. The pia matter on the lateral lip of the rhinal sulcus was cauterized, and the cortex on the lateral bank of the rhinal sulcus as well as $2 \mathrm{~mm}$ of tissue lateral to it was aspirated until reaching the posterior tip of the rhinal sulcus.

\section{Apparatus and materials}

Training was conducted in a standard Wisconsin General Testing Apparatus (WGTA), located inside a darkened, sound-shielded room. Ambient noise was masked by the use of a white noise generator. For the transverse patterning task, the testing tray $(30 \times 63 \mathrm{~cm})$ contained two food wells located 2 inches on either side of its center, and the discriminanda were 12 junk objects that had not been used in any previous behavioral tests. For DNML, the testing tray $(30 \times 63 \mathrm{~cm})$ consisted of nine wells arranged in rows of three $(10 \mathrm{~cm}$ apart from center to center). Two identical blue plaques $(5 \times 5 \mathrm{~cm})$ were used to cover the wells. Banana-flavored pellets (300 mg; P. J. Noyes, Lancaster, NH) or dried raisins served as reward.

\section{Behavioral procedures}

Pretraining. Before formal testing on transverse patterning, each monkey was trained on a simple concurrent discrimination task consisting of three object pairs (e.g., cup vs ball, box vs jar, bottle vs football). For each pair, one of the two objects was always rewarded. Subjects received 30 trials per each daily session for five sessions (total of 150 trials, 50 trials per discrimination). Problems were presented in blocks of five trials in 
Table 3. Transverse patterning training design

\begin{tabular}{lllll}
\hline & Phase 1 & Phase 2 & Phase 3 & Transfer $^{a}$ \\
\hline Set 1 & (1) $A+$ versus $B-$ & (1) $A+$ versus $B-$ & (1) $A+$ versus $B-$ & (1) $A+$ versus $B-$ \\
& & (2) $B+$ versus $C-$ & $(2) B+$ versus $C-$ & (2) $B+$ versus $C-$ \\
Set 2 & (1) $D+$ versus $E-$ & (1) $D+$ versus $A-$ & (3) $C+$ versus $X-$ \\
& & (2) $E+$ versus $E-$ & (1) $D+$ versus $E-$ & (1) $D+$ versus $E-$ \\
& & (2) $E+$ versus $F-$ & (2) $E+$ versus $F-$ \\
& & (3) $F+$ versus $D-$ & (3) $F+$ versus $Y-$
\end{tabular}

Problems trained concurrently in each phase. The problem set alternates every trial; however, which set begins each session is determined randomly. Each object is rewarded equally often on the left and right wells. Data are reproduced with permission from Alvarado and Bachevalier (2004).

${ }^{a}$ One possible example of the transfer set for a subject that could not solve phase 3 .

varying order for the first two sessions, in blocks of two trials for the third session, and in blocks of one or two trials for the last two sessions, with the order of presentation varying pseudorandomly.

Transverse patterning task. The training procedure was identical to that described by Alvarado and Bachevalier (2005). Briefly, monkeys were concurrently trained on two transverse patterning problem sets formed from six objects, $\mathrm{A}-\mathrm{F}$ ( set $1: \mathrm{A}+/ \mathrm{B}-, \mathrm{B}+/ \mathrm{C}-, \mathrm{C}+/ \mathrm{A}-$; set $2: \mathrm{D}+/ \mathrm{E}-$, $\mathrm{E}+/ \mathrm{F}-, \mathrm{F}+/ \mathrm{D}-)$. Within a session, the problem set alternated on every trial (e.g., set 1 was presented on odd trials, and set 2 was presented on even trials); however, whether set 1 was odd or even on a given day was determined pseudorandomly. The order of presentation within a problem set was also determined pseudorandomly, with the restriction that each problem appear at least once every 10 trials. Finally, training was divided into three phases. Phase 1 consisted of training on problem 1 of each set, phase 2 consisted of concurrent training on problems 1 and 2 from each set, and phase 3 consisted of concurrent training on the three problems from each set (Table 3).

For phase 1, a daily session consisted of 10 trials of each training problem presented in blocks of five trials for the first session, and then reducing the number of trials per block on subsequent daily session until the two problems reoccurred every one or two trials. The criterion was set at $90 \%$ or better for two consecutive sessions, with a minimum of $80 \%$ correct on a given problem.

For phase 2, the second problem in each set was introduced. On the first session of phase 2 , subjects received a block of five trials of $A+/ B-$, followed by 10 trials each of $\mathrm{B}+/ \mathrm{C}-$ and $\mathrm{E}+/ \mathrm{F}-$ and then five trials of $\mathrm{D}+/ \mathrm{E}-$ (the problem set alternated after each block of trials). Over the next three sessions, the trial-block size was decreased progressively to one, so for session five and thereafter, the problem set alternated on every trial. Presentation order within a set, however, varied pseudorandomly. The criterion was $90 \%$ correct or better for four consecutive sessions and a minimum of $80 \%$ correct for each problem.

For the first session in phase 3 , subjects received 5 trials each of problems 1 or 2 from each set, followed by 10 trials each of $\mathrm{C}+/ \mathrm{A}-$ and $\mathrm{F}+/ \mathrm{D}-$, then 5 trials each of the remaining discriminations (40 trials total). Thus, an example of a 40 trial daily session could be the following: 5 trials of $\mathrm{A}+/ \mathrm{B}-, 5$ trials $\mathrm{E}+/ \mathrm{F}-, 10$ trials of $\mathrm{C}+/ \mathrm{A}-, 10$ trials of $\mathrm{F}+/ \mathrm{D}-, 5$ trials of $\mathrm{B}+/ \mathrm{C}-$, and 5 trials of $\mathrm{D}+/ \mathrm{E}-$. Thereafter, monkeys received 30 trials per day, divided equally among all six discrimination problems, and problems were increasingly intermixed such that after session four, problems and sets alternated on every trial. The criterion for each set was determined independently and was set at 27 correct of 30 trials for 60 consecutive trials, with a minimum performance level of $80 \%$ on any single discrimination. Subjects were trained for a maximum of 2010 trials (1005 per set), and if they failed to reach the criterion, they were assigned a score of 1005 for that set. Finally, although the criterion for each set was determined independently, all six discrimination problems were presented until the criterion had been reached on each set.

Transverse patterning transfer. Subjects unable to reach the criterion on phase 3 of the transverse patterning task were given a transfer test to confirm that their impairment was not simply because of an inability to learn several discrimination problems with overlapping elements. Thus, in the transfer phase (Table 3), one problem from each set was altered so that an elemental or linear solution could be used to solve the sets. In other words, for each set, the specific problem on which the monkey had shown the lowest performance level was altered so that a previously untrained object was substituted for the unrewarded member of the pair. For example, replacing the unrewarded object in problem 3 with $\mathrm{X}-$ produced the set $\mathrm{A}+/ \mathrm{B}-, \mathrm{B}+/ \mathrm{C}-, \mathrm{C}+/ \mathrm{X}-$ and yielded the linear solution $\mathrm{A}>\mathrm{B}>\mathrm{C}>\mathrm{X}$. A similar substitution was made in set 2 with a new object, $\mathrm{Y}-$ (Table 3). Transfer training began the day after the animals failed to reach the criterion, and no overt introduction was made to the new problems. Training continued on these sets until the animals reached the criterion as described above.

$D N M L$. After transverse patterning training, and before training on DNML, the subjects were trained on the VPC and the DNMS with trialunique objects, including a version with distracters inserted into the delay (Nemanic et al., 2004). The procedures for DNML have been described in detail previously (Málková et al., 1995). Briefly, as for DNMS, each trial consisted of a sample and a choice phase, but in the choice phase, the comparison was between a familiar and a novel location on the 9-well tray. During the sample phase, one of the nine wells was baited and covered with a plaque. The monkey displaced the plaque to retrieve the reward. Ten seconds later, the monkey chose between the unbaited sample well and a new baited well, both covered by identical plaques. After the choice phase, there was a 30 s intertrial interval, after which the next trial began, using two different locations on the tray. Each daily session consisted of 20 trials using one of six predetermined, pseudorandom sequences of 20 location pairs. The criterion was set at 90 correct of 100 consecutive choices, with a maximum of 1000 training trials. Animals failing to reach the criterion were allowed up to 500 additional trials in which the sample location was presented twice, separated by a $10 \mathrm{~s}$ inter$\mathrm{val}$, and the well was baited pseudorandomly on either the first or second presentation.

The subjects were then given a performance test in which the delay between the sample and choice phases increased to 30, 60, 120, and $600 \mathrm{~s}$. Monkeys received 100 trials (20 trials per session for 5 consecutive days) at the 30,60 , and $120 \mathrm{~s}$ delays and 50 trials ( 5 trials per session for 10 consecutive days) at the 10 min delay. Monkeys remained inside the WGTA at all times during testing, including the longest delays.

Behavioral data analysis. Multifactorial ANOVAs were used with groups (three) for between-subjects comparisons and variables (with repeated measures when appropriate) for within-subjects comparisons. For all variables with repeated measures, degrees of freedom were corrected with Huynh-Feldt $\epsilon$. Post hoc comparisons were performed using a Tukey test. One-way ANOVAs or paired $t$ tests were used to evaluate within-group evolution of performance across testing conditions. A onesided $t$ test was used to compare performance to chance level. KruskalWallis and Mann-Whitney $U$ tests were used for analyses of all nonparametric measures, including trials to criterion, for which the variance was not homogeneous.

\section{Histology}

At the end of behavioral testing, the operated subjects were sedated and given a lethal dose of sodium pentobarbital, then perfused intracardially with $0.9 \%$ saline followed by $4 \%$ paraformaldehyde. The brains were photographed, cryoprotected, and cut frozen at $50 \mu \mathrm{m}$ in the coronal plane. Every fifth section was mounted and stained with thionin to visualize cell bodies. Histological sections were analyzed microscopically to determine the extent of cell loss and presence of gliosis.

To assess lesion extent, histological sections were matched with digitized drawings of coronal sections at $1 \mathrm{~mm}$ intervals through a normal monkey brain. The extent of cell loss and gliosis on each section were drawn on each coronal section of the normal monkey. Using Image software (Scion, Frederick, MD), the extent of intended damage to the cortical areas, as well as of unintended damage to adjacent structures, was measured on each section, and the percentage of damage for each structure (compared with the normal brain) was calculated.

\section{Results}

\section{Lesion evaluation}

An extensive description and reproduction of areas TH/TF and perirhinal damage has been published recently [see Nemanic et al. (2004), their Figs. 4-6 for perirhinal damage and Figs. 7 and 8 
Table 4. Intended and unintended damage in group TH/TF

\begin{tabular}{|c|c|c|c|c|c|c|c|c|c|c|c|c|}
\hline \multirow[b]{2}{*}{ Subjects } & \multicolumn{4}{|l|}{$\mathrm{TH}$} & \multicolumn{4}{|l|}{ TF } & \multicolumn{4}{|l|}{ Total } \\
\hline & $\mathrm{L}$ & $\mathrm{R}$ & Avg & W & $\mathrm{L}$ & $\mathrm{R}$ & Avg & W & $L$ & $\mathrm{R}$ & Avg & W \\
\hline TH/TF-1 & 68 & 66 & 67 & 45 & 64 & 66 & 65 & 35 & 66.4 & 66 & 66.3 & 40.3 \\
\hline TH/TF-2 & 93 & 85 & 89 & 79 & 93 & 89 & 91 & 83 & 92.9 & 87 & 90.1 & 81 \\
\hline TH/TF-3 & 72 & 96 & 84 & 69 & 92 & 93 & 92 & 85 & 82 & 94 & 88 & 77 \\
\hline \multirow[t]{2}{*}{ Average } & 78 & 82 & 80 & 65 & 83 & 83 & 83 & 68 & 80.5 & 82.5 & 81.5 & 66.1 \\
\hline & \multicolumn{4}{|l|}{ CA1 } & \multicolumn{4}{|c|}{ Subicular complex } & \multicolumn{4}{|l|}{ ERh } \\
\hline Subjects & $\mathrm{L}$ & $\mathrm{R}$ & Avg & W & $\mathrm{L}$ & $\mathrm{R}$ & Avg & W & $\mathrm{L}$ & $\mathrm{R}$ & Avg & W \\
\hline TH/TF-1 & 0.0 & 0.0 & 0.0 & 0.0 & 0.0 & 0.0 & 0.0 & 0.0 & 0.0 & 0.0 & 0.0 & 0.0 \\
\hline TH/TF-2 & 4.2 & 0.0 & 2.1 & 0.0 & 35.4 & 0.0 & 17.7 & 0.0 & 8.6 & 0.0 & 4.3 & 0.0 \\
\hline TH/TF-3 & 0.0 & 0.0 & 0.0 & 0.0 & 0.0 & 0.0 & 0.0 & 0.0 & 0.0 & 0.0 & 0.0 & 0.0 \\
\hline \multirow[t]{2}{*}{ Average } & 1.4 & 0.0 & 0.7 & 0.0 & 11.8 & 0.0 & 5.9 & 0.0 & 2.87 & 0.0 & 1.43 & 0.0 \\
\hline & \multicolumn{4}{|l|}{ PRh } & \multicolumn{4}{|l|}{ TE } & \multicolumn{4}{|l|}{ TEO } \\
\hline Subjects & $\mathrm{L}$ & $\mathrm{R}$ & Avg & W & $\mathrm{L}$ & $\mathrm{R}$ & Avg & W & L & $\mathrm{R}$ & Avg & W \\
\hline TH/TF-1 & 0.96 & 12.6 & 6.78 & 0.12 & 0.22 & 7.9 & 4.06 & 0.02 & 0.0 & 0.13 & 0.07 & 0.0 \\
\hline TH/TF-2 & 8.1 & 8.1 & 8.1 & 0.66 & 4.1 & 4.6 & 4.35 & 0.19 & 2.9 & 1.2 & 2.05 & 0.04 \\
\hline TH/TF-3 & 1.8 & 4.4 & 3.1 & 0.08 & 1.2 & 0.0 & 0.6 & 0.0 & 0.0 & 1.1 & 0.55 & 0.0 \\
\hline Average & 3.62 & 8.37 & 5.99 & 0.29 & 1.84 & 4.17 & 3.00 & 0.07 & 0.97 & 0.81 & 0.89 & 0.01 \\
\hline
\end{tabular}

Data are the estimated (percentage of normal) intended damage to cytoarchitectonic fields TH and TF (von Bonin and Bailey, 1947) and unintended damage to field CA1 of the hippocampus, the subicular complex, entorhinal area 28 (ERh), perirhinal cortical areas 35 and 36 (PRh), and cytoarchitectonic fields TE and TEO (von Bonin and Bailey, 1947). L, Percentage of damage to the left hemisphere; $R$, percentage of damage to the right hemisphere; Avg, average of $L$ and R; $W$, $W=(L \times R) / 100$ (weighted index as defined by Hodos and Bobko, 1984). Data are presented with permission from Nemanic et al. (2004).

for TH/TF damage (reproduced as supplemental material, available at www.jneurosci.org) ]. A brief summary of lesion extent for each case is provided here.

\section{TH/TF lesions}

Summary of the extent of intended and unintended damage for each case is given in Table 4 and Figure 1. Removals of areas $\mathrm{TH} / \mathrm{TF}$ were bilaterally extensive in cases TH/TF-2 and TH/TF-3, reaching 90 and $88 \%$, respectively. In the remaining case, the removal was also bilaterally symmetrical but was less complete $(66 \%)$ because of sparing of the caudalmost portion of the parahippocampal areas. Except for 35\% damage to the left subicular complex in case TH/TF-2, inadvertent damage to temporal cortical areas remained minimal $(<10 \%)$ in this group.

\section{Perirhinal lesions}

Summary of the extent of intended and unintended damage for each case is given in Table 5 and Figure 2. Briefly, damage to the PRh was bilaterally extensive in all cases, ranging from 83 to $91 \%$. Unintended damage to the entorhinal cortex was moderate $(<30 \%)$ in all cases. Rostrally, the lesions involved the medial part of polar area TG [i.e., the portion that has been proposed as a rostral extension of PRh by Suzuki and Amaral (1994a,b)] in cases PRh-3 and PRh-5 bilaterally and unilaterally in case PRh-2. Laterally, inadvertent damage to visual area TE was minor $(<10 \%)$ in cases PRh-2, PRh-3, and PRh-4 but moderate $(>30 \%)$ in case PRh- 5. In the latter case, this damage extended further laterally to include both banks of the superior temporal sulcus. All cases sustained only minor damage $(<10 \%)$ to parahippocampal areas $\mathrm{TH}$ and $\mathrm{TF}$, but the hippocampal formation was left intact. In addition, inspection of the silver impregnated sections indicate that substantial damage to the white matter just beneath the cortical lesion occurred in case PRh-5, although in the other cases, mild inadvertent damage to the white matter adjacent to the actual aspiration removal could have occurred but cannot be appreciated from the histological material.

\section{Transverse patterning}

Pretraining

Results are reported for three subjects in group $\mathrm{N}$ and all subjects in groups TH/TF and PRh (Table 1). All subjects learned the basic task demands and the three pretraining discrimination problems. At the end of training, group $\mathrm{N}$ had an average performance rate of $100 \%$ correct, and group TH/TF performed at an average of $97 \%$ correct. Similarly, group PRh performed at $97 \%$ correct, on average, for the three problems on the last session of pretraining, although one subject, PRh-4, was given an extra training session because she had learned two problems but was at chance for the third one. After this extra session, this animal's performance reached $97 \%$ correct.

\section{Training}

The comparison of acquisition of the three phases of transverse patterning was made between the three subjects in group $\mathrm{N}$ that received training in phases (Table 1 ) and in all experimental subjects. Because there was no effect of training set for either group $(p>0.05)$, all results are presented collapsed across sets 1 and 2 . The average trials to criterion for each training phase and the transfer phase are presented in Figure 3. Because there was very little variance within the groups in each phase, and because the training cap of 1005 trials skewed the distribution in the lesion groups in phase 3, each phase was analyzed with the nonparametric Kruskal-Wallis test, rather than an ANOVA with phase as the repeated measure.

Acquisition of phases 1 and 2 was identical for the three groups. All animals reached the criterion on the first problem of both training sets ( 32 trials, on average, for the three control subjects, 39 trials for group PRh, and 33 trials for group TH/TF). Performance in phase 2 was, likewise, equal across all groups, and the average number of trials to criterion was 75 trials for group N, 83 trials for group TH/TF, and 82 trials for group PRh. A Kruskal-Wallis analysis of the trials to reach the criterion in either phase revealed no significant difference between groups (phase 1: $H_{(2)}=0.84, p>0.05$; phase 2: $H_{(2)}=1.64, p>0.05$ ).

The transition to phase 3 impacted all groups, but not equally. All animals in group $\mathrm{N}$ learned the six transverse patterning discriminations, requiring 522 trials, on average, to reach the criterion. In contrast, group $\mathrm{TH} / \mathrm{TF}$ required 925 trials, and group $\mathrm{PRh}$ required 944 trials, on average, to reach the criterion. Of the two experimental groups, only case TH/TF-1 was able to solve both sets of problems in 690 and 960 trials, respectively. One 

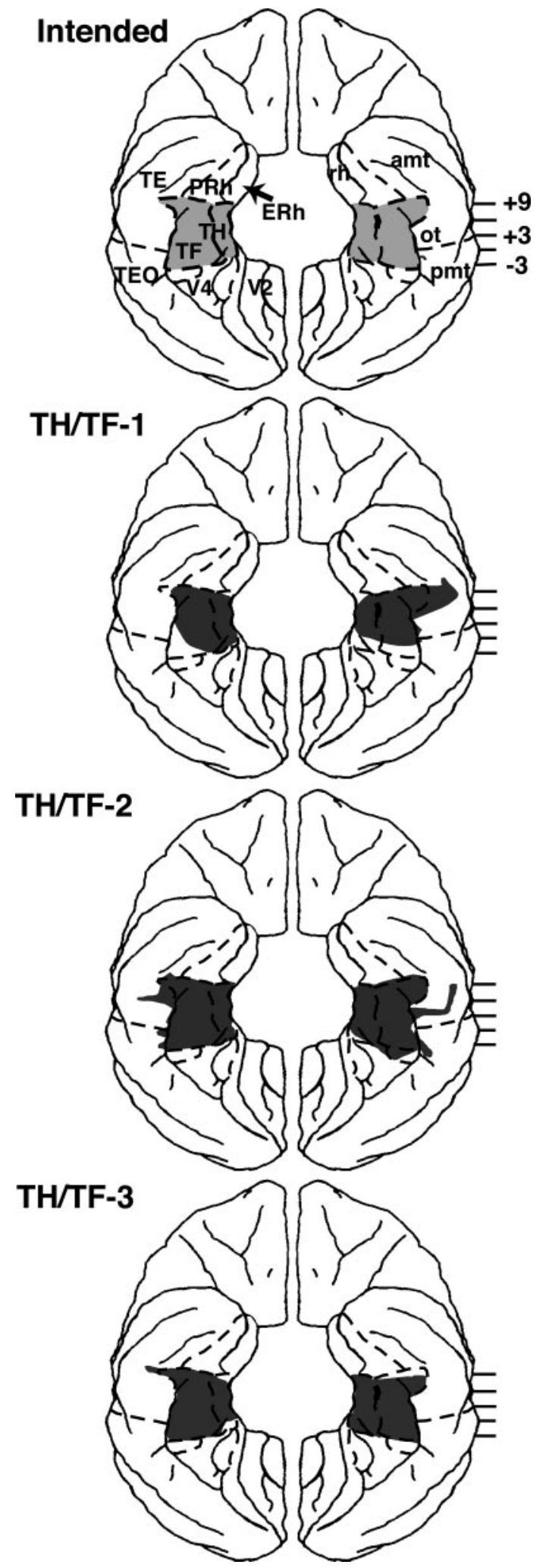

Figure 1. Intended lesion and surface reconstructions of actual damage for group TH/TF. For detailed reconstruction on coronal sections and histological sections, see Nemanic et al. (2004), their Figures 7 and 8 (reproduced as supplemental material, available at www.jneurosci.org). Numerals on the right indicate the approximate distance in millimeters from the interaural plane. amt, Anterior middle temporal sulcus; ERh, entorhinal cortex; pmt, posterior middle temporal sulcus; rh, rhinal sulcus; ot, occipitotemporal sulcus; TE, TE0, TH, and TF, cytoarchitectonic fields as described by von Bonin and Bailey (1974). subject in each group solved one set but failed to solve the second (case TH/TF-2 required 885 trials, and case $\mathrm{PRh}-4$ required 515 trials). Finally, one subject in group TH/TF and two subjects in group PRh failed to solve both problem sets. Thus, although both experimental groups solved the first two phases of transverse patterning as rapidly as controls, they were impaired in phase 3 of the transverse patterning task. This was confirmed by a KruskalWallis analysis of trials to criterion for phase 3 that revealed a main effect of group that narrowly missed significance $\left(H_{(2)}=\right.$ 5.61; $p<0.06)$, although each group differed from controls $(U=$ 0.0 and $p<0.05$ for group TH/TF; $U=0.0$ and $p<0.046$ for group PRh).

Results for performance levels at the end of phase 3 include all seven subjects in group $\mathrm{N}$, because their phase 3 training was identical after the blocked trials. Performance averaged over the last $5 \mathrm{~d}$ of training (including $4 \mathrm{~d}$ of criterion, if achieved on those days) and collapsed across the problem set (i.e., problem 1 refers to the performance on the first discrimination problem averaged across the two sets) is presented in Figure $4 \mathrm{~A}$. By the end of training, all subjects in group $\mathrm{N}$ were performing above $80 \%$ correct on the six transverse patterning discriminations. In contrast, groups TH/TF and PRh performed well below this level. To better represent the performance patterns of each group across the three problems of both sets, the performance scores of each animal was ranked according to their best, intermediate, and worst performance on both sets. Presented this way (Fig. 4B), it is clear that group $\mathrm{N}$ was performing well on all problems, truly indicating that they had solved the task. Subjects in group TH/TF performed as well as controls on one problem, less well so on the second, and near chance on the third. Similarly, group PRh performed well on one problem, above chance on the second, but near chance on the third.

The overall impairment of both lesion types was confirmed by a two-way ANOVA of group $\times$ problem, with repeated measures on the problem variable, that yielded a main effect of group $\left(F_{(2,11)}=0.219 ; p<0.04\right)$, no effect of problem, but a group $\times$ problem interaction $\left(F_{\text {Huynh-Feldt }(4,22)}=3.51 ; p<0.023\right)$. When the data were analyzed by performance rank (best, intermediate, worst) instead of problem, the ANOVA yielded a main effect of rank $\left(F_{\text {Huynh-Feldt }(2,22)}=79.05 ; p<0.0001\right)$ and a group $\times$ rank interaction $\left(F_{\text {Huynh-Feldt }(4,22)}=6.72 ; p<0.001\right)$ in addition to the group main effect. Separate group analyses between group $\mathrm{N}$ and each experimental group were conducted to further explore this interaction. A comparison with group TH/TF yielded no main effect of group $\left(F_{(1,8)}=3.87 ; p>0.05\right)$ but an effect of rank $\left(F_{\text {Huynh-Feldt }(2,16)}=38.63 ; p<0.001\right)$ and a group $\times$ rank interaction $\left(F_{\text {Huynh-Feldt } 2,16)}=7.63 ; p<0.01\right)$. Univariate $F$ tests showed the group effect to be reliable at the intermediate rank $(p<0.047)$ but just missed significance at the worst rank ( $p<$ $0.06)$. A comparison between group $\mathrm{N}$ and group PRh yielded a main effect of group $\left(F_{(1,9)}=15.23 ; p<0.004\right)$ and of rank $\left(F_{\text {Huynh-Feldt }(2,18)}=93.91 ; p<0.001\right)$ and a group $\times$ rank interaction $\left(F_{\text {Huynh-Feldt(2,18) }}=17.58 ; p<0.001\right)$. Univariate $F$ tests revealed that, although the magnitude of group difference increased across rank, the group difference was reliable at each rank $($ all $p<0.01)$.

\section{Transfer}

Subjects that failed to reach the criterion on a particular set were transferred to a linear version of that set (Table 3). For those subjects that reached the criterion on a single set, they were trained on the transfer set for the set that they failed to learn, while concurrently continuing the transverse patterning set that 
Table 5. Intended and unintended damage in group PRh

\begin{tabular}{|c|c|c|c|c|c|c|c|c|c|c|c|c|}
\hline \multirow[b]{2}{*}{ Subjects } & \multicolumn{4}{|l|}{ PRh } & \multicolumn{4}{|l|}{ ERh } & \multicolumn{4}{|l|}{ TG } \\
\hline & $\mathrm{L}$ & $\mathrm{R}$ & Avg & W & $\mathrm{L}$ & R & Avg & W & L & $R$ & Avg & W \\
\hline PRh-2 & 82.3 & 83.8 & 83.1 & 69.0 & 4.3 & 11.7 & 8.0 & 0.5 & 0.0 & 31.7 & 15.9 & 0.0 \\
\hline PRh-3 & 95.2 & 82.4 & 88.8 & 78.4 & 18.7 & 13.1 & 15.9 & 2.45 & 22.4 & 23.3 & 22.9 & 5.22 \\
\hline PRh-4 & 92.8 & 90.1 & 91.5 & 83.6 & 15.6 & 15.2 & 15.4 & 2.37 & 0.0 & 0.0 & 0.0 & 0.0 \\
\hline PRh-5 & 94.9 & 85.6 & 84.0 & 81.2 & 21.3 & 33.6 & 27.5 & 7.16 & 35.5 & 29.2 & 32.4 & 10.4 \\
\hline \multirow[t]{2}{*}{ Average } & 91.5 & 84.3 & 86.7 & 77.2 & 15.8 & 17.0 & 16.4 & 2.93 & 22.4 & 36.3 & 29.4 & 13.6 \\
\hline & \multicolumn{4}{|l|}{ TE } & \multicolumn{4}{|l|}{ TH } & \multicolumn{4}{|l|}{ TF } \\
\hline Subjects & $\mathrm{L}$ & $R$ & Avg & W & $\mathrm{L}$ & R & Avg & W & L & $R$ & Avg & W \\
\hline PRh-2 & 2.8 & 16.1 & 9.45 & 0.45 & 14.6 & 0.0 & 0.0 & 0.0 & 10.1 & 3.5 & 6.8 & 0.35 \\
\hline PRh-3 & 9.6 & 6.4 & 8.0 & 0.61 & 2.2 & 2.7 & 2.45 & 0.06 & 2.2 & 2.2 & 2.2 & 0.05 \\
\hline PRh-4 & 7.8 & 6.2 & 7.0 & 0.48 & 0.0 & 2.2 & 1.1 & 0.0 & 5.6 & 0.4 & 3.0 & 0.02 \\
\hline PRh-5 & 40.7 & 21.5 & 31.1 & 8.75 & 8.6 & 0.0 & 4.3 & 0.0 & 6.0 & 12.4 & 9.2 & 0.74 \\
\hline Average & 16.0 & 21.8 & 18.9 & 4.32 & 5.08 & 0.98 & 3.03 & 0.01 & 6.14 & 5.26 & 5.7 & 0.34 \\
\hline
\end{tabular}

Data are the estimated (percentage of control) intended damage to perirhinal cortical areas 35 and 36 (PRh) and unintended damage to adjacent cortical regions. Conventions are as in Table 3. Data are presented with permission from Nemanic et al. (2004).

\section{Intended}

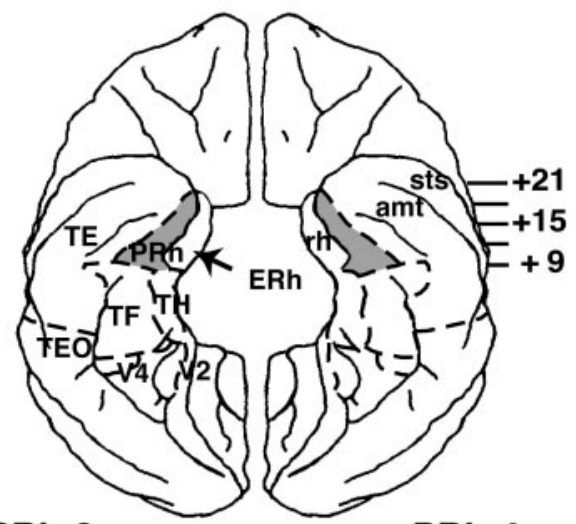

PRh-2

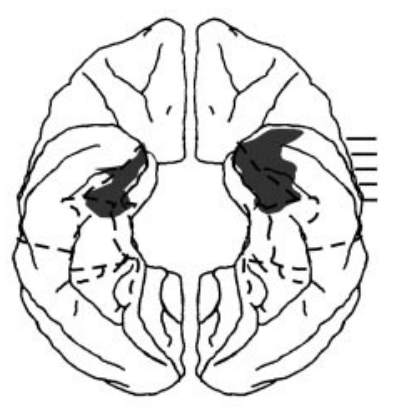

PRh-3

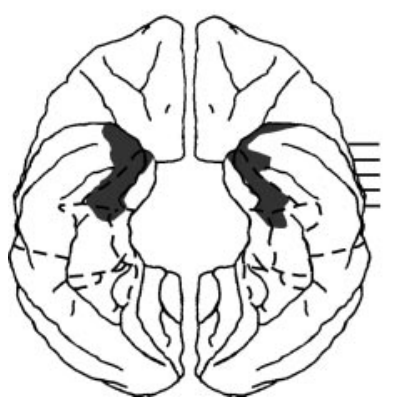

PRh-4

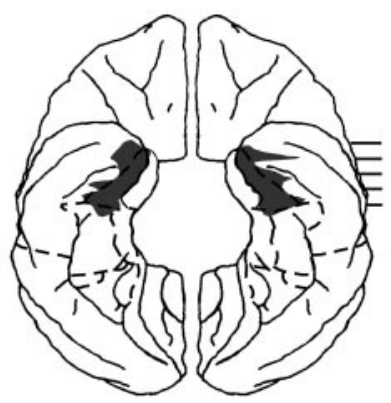

PRh-5

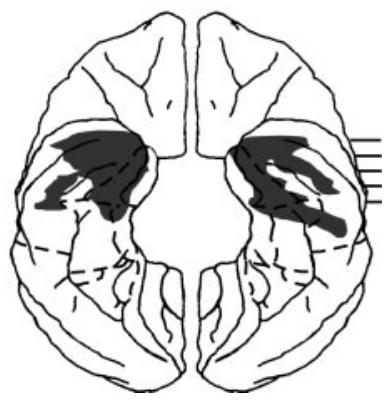

Figure 2. Intended lesion and surface reconstructions of actual damage for group PRh. For detailed reconstruction on coronal sections and histology of a representative case, see Nemanic et al. (2004), their Figures 4-6 (reproduced as supplemental material, available at www. jneurosci.org). sts, Superior temporal sulcus. All other abbreviations are as in Figure 1.

was learned. Thus, subjects TH/TF-3, PRh-2, PRh-3, and PRh-5 were transferred on both sets, whereas subjects TH/TF-2 and PRh-4 were transferred on only the unlearned set. Training for all five subjects continued until they reached the criterion for each set (whether transfer or transverse patterning).

As shown in Figure 3 (transfer), subjects in both groups learned the new elemental discriminations quickly, reaching the criterion in an average of 145 and 216 trials compared with their training performance ( 925 and 923 trials for groups TH/TF and $\mathrm{PRh}$, respectively). Their improved performance at the end of the transfer phase is further illustrated in Figure $4 B$ (right). Compared with their performance on transverse patterning, all subjects performed at $80 \%$ correct or better, on average, on the three problems.

\section{DNML: acquisition and performance}

The results for DNML are presented in Table 6 (left columns). Comparisons for DNML were made between all cases in groups $\mathrm{TH} / \mathrm{TF}$ and $\mathrm{N}$ and in three subjects in group PRH (subject PRh-2 was not tested on this task). Comparison scores for performance on DNMS at similar delays are presented in the right columns of Table 6 [see Nemanic et al. (2004) for additional analysis of these data]. Despite experience with DNMS, acquisition of the spatial task was difficult for all groups. Group N required 551 trials to reach the criterion (compared with 125 for DNMS), and two subjects required correction-training trials beyond the 1000 trials limit to reach the criterion. Group TH/TF required 953 trials, on average (compared with 524 for DNMS). Furthermore, subjects

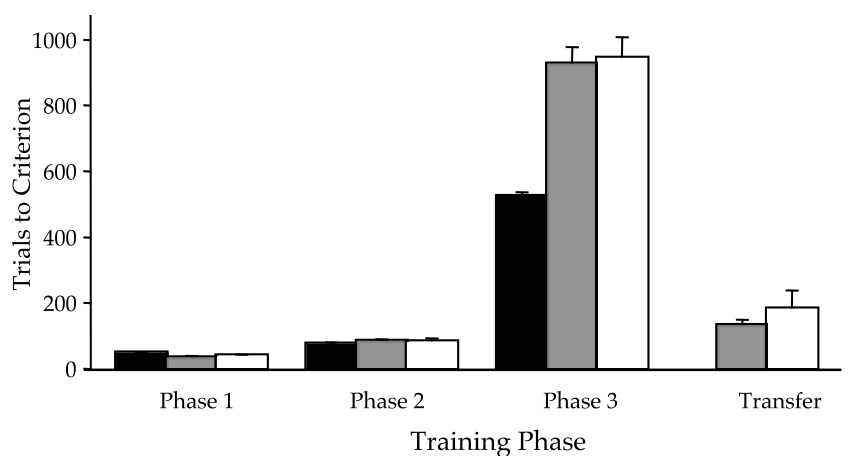

Figure 3. Acquisition of transverse patterning phases $1-3$ and transfer. Trials to criterion of three subjects in group $\mathrm{N}$ who received phase training (filled bars), group PRh (gray bars), and group TH/TF (open bars) are shown. 


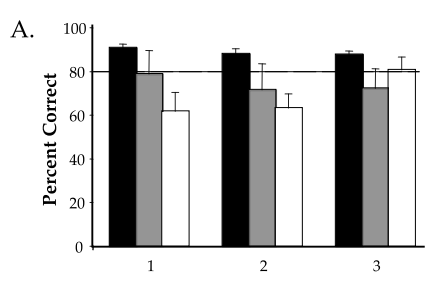

Training Problem
B.

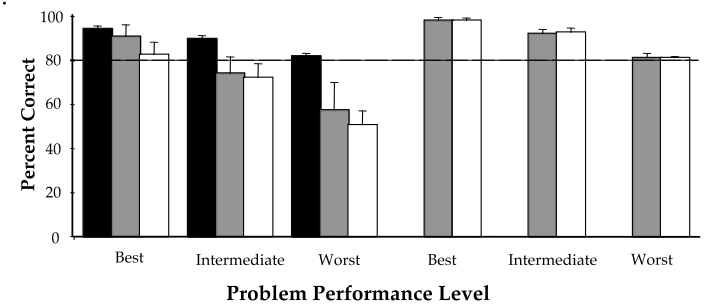

Figure 4. Performance of transverse patterning averaged across the last five training sessions. Group $\mathrm{N}$ includes all seven subjects. $A$, Percentage of correct performance on each problem of transverse patterning, averaged across sets 1 and 2 (i.e., training problem $1=$ averaged performance across the first 2 discriminations of each problem set). $B$, Left, Percentage of correct performance plotted by problem rank (i.e., the best, intermediate, and worst performance levels averaged across the 2 sets). Right, Performance as a function of problem rank on the transfer set of problems for groups TH/TF and PRh. Conventions are as in Figure 3.

TH/TF-1 and TH/TF-3 failed to reach the criterion within the limits of training and were given correction-training sessions. Even with that additional training, subject $\mathrm{TH} / \mathrm{TF}-1$ only reached $80 \%$ correct before moving on to delays, but subject TH/TF-3 never performed higher than chance, even after 500 additional correction trials, and so was given a score of $56 \%$ (his highest score after acquisition and correction) for all delays. Finally, group PRh required 886 trials compared with 757 on DNMS, but only case PRh-4 showed an increase in trials to criterion (Table 6). Subject PRh-3 required extra training beyond the training limits. With this extra training, PRh-3 achieved $77 \%$ correct performance before moving on to the delays. Although all subjects found the task to be difficult, group $\mathrm{N}$ learned faster than either lesion group ( $\mathrm{N}$ vs TH/TF: Mann-Whitney $U$ test $=2, p<0.05$; $\mathrm{N}$ vs PRh: Mann-Whitney $U$ test $=2, p<0.05$ ).

As shown in Table 6, performance for all groups declined across delays, with group $\mathrm{N}$ performing the best of the three groups. Performance of group TH/TF was consistently the lowest and worsened as delays increased. With the exception of the $120 \mathrm{~s}$ delay, group PRh performed like the control group. A group $\times$ delay ANOVA with repeated measures for delay yielded a significant main effect of group $\left(F_{(2,10)}=4.927 ; p<0.03\right)$ and of delay $\left(F_{\text {Huynh-Feldt }(3,30)}=12.67 ; p<0.0001\right)$ but no interaction. Further examination of the group effect showed that only group $\mathrm{TH} / \mathrm{TF}$ differed from group $\mathrm{N}$ (Tukey test; $p<0.03$ ), whereas the two experimental groups did not differ from each other $(p>0.05)$.

The pattern of performance across DNML delays for the two experimental groups contrasts with that across the DNMS delays (Table 6, right columns). Briefly, whereas group PRh performed worse than group $\mathrm{N}$ at all delays of DNMS, group TH/TF performed worse than group $\mathrm{N}$ only at the longest delay of this task. This pattern of results was confirmed by a group $\times$ delay ANOVA indicating a significant effect of group $\left(F_{(2,10)}=11.27 ; p<0.003\right)$ and of delay $\left(F_{\text {Huynh-Feldt(3,30) }}=22.74 ; p<0.0001\right)$ as well as a significant group $\times$ delay interaction $\left(F_{\text {Huynh-Feldt(6,30) }}=6.43\right.$; $p<0.003$ ). Further exploration of the interaction indicated that group PRh differed from group $\mathrm{N}$ at the 30,120 , and 600 s delays and from group $\mathrm{TH} / \mathrm{TF}$ at $600 \mathrm{~s}$ (Tukey test; all $p<0.05$ ). In contrast, group $\mathrm{TH} / \mathrm{TF}$ differed from group $\mathrm{N}$ only at the $600 \mathrm{~s}$ delay $(p<0.05)$.

The overall comparison between groups on object versus location recognition memory is summarized in Figure 5. Whereas the location task was more difficult to learn for most subjects, there was a dissociation of the effect of lesion on performance of the two tasks. As revealed by the individual analyses above, group PRh was impaired relative to controls on DNMS but not on DNML. In contrast, group TH/TF was impaired relative to con- trols on DNML but not on DNMS, except at the longest delay. A dissociation between task performance and lesion type was suggested by a comparison of overall performance on the two tasks (collapsed across the four delays). The ANOVA yielded a significant main effect of group $\left(F_{(2,10)}=8.468 ; p<0.007\right)$ and of task $\left(F_{(1,10)}=22.5 ; p<0.001\right)$, as well as a significant group $\times$ task interaction $\left(F_{(2,10)}=6.887 ; p<0.013\right)$. Further exploration of the interaction (Tukey) revealed that for DNMS, group $\mathrm{N}$ differed from group PRh $(p<0.002)$ but not from $\mathrm{TH} / \mathrm{TF}(p>0.05)$, and the overall difference between the experimental groups narrowly missed significance $(p<0.09)$. In contrast, group $\mathrm{N}$ differed from group TH/TF on DNML $(p<0.03)$ but not from group PRh $(p>0.05)$. However, the two experimental groups did not differ from each other $(p>0.05)$.

\section{Comparisons between cortical versus hippocampal lesions}

Areas TH/TF and PRh, respectively, are the last stages of the "where" and "what" visual pathways, respectively, and convey that information to the hippocampus. In the interest of discerning whether these regions contribute differently to memory processes, we now compare the results of the present study to those recently obtained with selective hippocampal lesions (group $\mathrm{H}$ ) in a previous study (Alvarado and Bachevalier, 2005). As summarized in Table 7, subjects in group $\mathrm{H}$ were impaired on phase 3 of transverse patterning and showed a clear decline in performance across the best, intermediate, and worst performance levels. They were also impaired on both acquisition and performance of DNML compared with controls as well as to their own performance on DNMS (Nemanic et al., 2004; Alvarado and Bachevalier, 2005). With respect to transverse patterning, all three lesions impacted acquisition and performance. For group $\mathrm{H}$, the degree of impairment depended on the extent of the lesion, which yielded no impairment in the case with the least damage, a partial impairment in two others, and a complete impairment in the case with the most extensive damage (Alvarado and Bachevalier, 2005). As a group, animals with TH/TF lesions were similar to group $\mathrm{H}$ : one subject with the least damage solved both problems (although he was impaired relative to controls), and one subject solved a single set. Group PRh was the most uniformly impaired, yet in this group also, a single subject solved one transverse patterning set. Comparisons of acquisition or performance of transverse patterning yielded no differences between the operated groups (all $p>0.05$ ). In contrast, comparisons of performance across DNMS and DNML did yield some differences.

The performance of group TH/TF mirrored that of group $\mathrm{H}$ in that the two groups did not differ from each other in performance on either DNMS or DNML; however, group TH/TF did differ from controls at 10 min on DNMS (Nemanic et al., 2004). In contrast, performance of group PRh appears to differ from that of group $\mathrm{H}$ on both tasks. Thus, group $\mathrm{PRh}$ was impaired relative to groups $\mathrm{H}$ and $\mathrm{N}$ on DNMS. Furthermore, although both groups $\mathrm{PRh}$ and $\mathrm{H}$ did not differ from each other on DNML, group PRh did not differ from controls, but group $\mathrm{H}$ did. Confirming this description, the main effect of group in a group $\times$ task $\times$ delay ANOVA narrowly missed significance $\left(F_{(3,13)}=2.94 ; p<0.07\right)$. There was, however, a main effect of task $\left(F_{(1,3)}=47.2 ; p<\right.$ $0.001)$ and of delay $\left(F_{\text {Huynh-Feldt(3,9) }}=64.24 ; p<0.001\right)$. Finally, 
Table 6. Acquisition and performance of DNML and DNMS

\begin{tabular}{|c|c|c|c|c|c|c|c|c|c|c|c|c|c|c|c|c|}
\hline \multirow[b]{2}{*}{ Case } & \multicolumn{3}{|c|}{ DNML acquisition } & \multicolumn{3}{|c|}{ Correction } & \multicolumn{5}{|c|}{ DNML delays } & \multicolumn{5}{|c|}{ DNMS delays } \\
\hline & TTC & $\mathrm{ETC}$ & Percentage & TTC & ETC & Percentage & $30 s$ & $60 s$ & $120 \mathrm{~s}$ & $600 s$ & Avg & $30 s$ & $60 s$ & $120 s$ & $600 s$ & Avg \\
\hline $\mathrm{N}-1$ & 510 & 101 & 91 & & & & 79 & 68 & 70 & 66 & 70.8 & 90 & 84 & 88 & 82 & 86.0 \\
\hline $\mathrm{N}-2$ & 1000 & 232 & 75 & 180 & 31 & 84 & 79 & 81 & 77 & 74 & 77.8 & 92 & 81 & 85 & 94 & 88.0 \\
\hline $\mathrm{N}-3$ & 510 & 168 & 90 & & & & 78 & 77 & 72 & 62 & 72.3 & 79 & 71 & 74 & 82 & 76.5 \\
\hline $\mathrm{N}-4$ & 200 & 34 & 90 & & & & 81 & 81 & 75 & 70 & 76.8 & 89 & 96 & 95 & 78 & 89.5 \\
\hline$N-5$ & 1000 & 286 & 87 & 120 & 15 & 90 & 84 & 83 & 79 & 84 & 82.5 & 89 & 86 & 90 & 86 & 87.8 \\
\hline N-6 & 480 & 89 & 90 & & & & 88 & 80 & 82 & 70 & 80.0 & 99 & 96 & 95 & 94 & 96.0 \\
\hline $\mathrm{N}-7$ & 160 & 25 & 90 & & & & 79 & 78 & 78 & 78 & 78.3 & 93 & 97 & 97 & 88 & 93.8 \\
\hline Average & 551.4 & 133.6 & 89.3 & & & & 81.1 & 78.3 & 76.1 & 72.0 & 76.9 & 90.1 & 87.3 & 89.1 & 86.3 & 88.2 \\
\hline TH/TF-1 & 1000 & 255 & 79 & 200 & 36 & 86 & 75 & 78 & 58 & 54 & 66.3 & 87 & 86 & 85 & 74 & 83.0 \\
\hline TH/TF-2 & 860 & 217 & 90 & & & & 78 & 73 & 73 & 60 & 71.0 & 82 & 84 & 85 & 76 & 81.8 \\
\hline TH/TF-3 & 1000 & 389 & 56 & 500 & 206 & 57 & 56 & 56 & 56 & 56 & 56.0 & 83 & 82 & 82 & 60 & 76.8 \\
\hline Average & 953.3 & 287.0 & 74.7 & & & & 69.7 & 69.0 & 62.3 & 56.7 & 64.4 & 84.0 & 84.0 & 84.0 & 70.0 & 80.5 \\
\hline PRh-3 & 1000 & 303 & 73 & 140 & 28 & 77 & 73 & 63 & 54 & 58 & 62.0 & 77 & 80 & 79 & 38 & 68.5 \\
\hline PRh-4 & 1000 & 207 & 92 & & & & 83 & 80 & 71 & 66 & 75.0 & 81 & 79 & 80 & 64 & 76.0 \\
\hline PRh-5 & 660 & 188 & 90 & & & & 75 & 83 & 68 & 78 & 76.0 & 77 & 67 & 69 & 44 & 64.3 \\
\hline Average & 886.7 & 232.7 & 86.3 & & & & 77.0 & 75.3 & 64.3 & 67.3 & 71.0 & 78.3 & 75.3 & 76.0 & 48.7 & 69.6 \\
\hline
\end{tabular}

Scores are the number of trials (TTC) and errors (ETC) preceding the learning criterion in DNML and correction training and performance scores (percentage) obtained during the criterion run in DNML and correction training. The percentage of correct responses over 100 trials for each extended delays of the DNML and DNMS is shown. The average is the mean percentage of correct responses across the four delays.

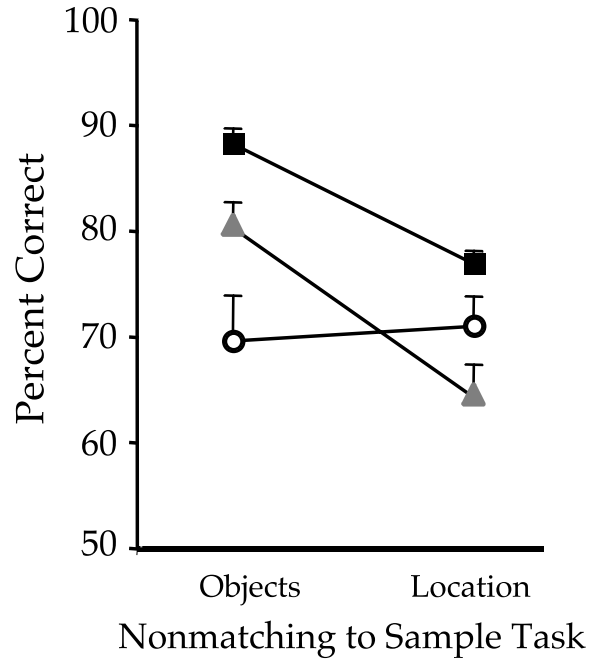

Figure 5. Performance on DNMS [data are from Nemanic et al. (2004)] and DNML, collapsed across the four delays. Filled squares, Group N; gray triangles, group TH/TF; open circles, group PRh.

Table 7. Comparison of cortical versus hippocampal damage

\begin{tabular}{llllllll}
\hline & \multicolumn{3}{c}{ Transverse patterning } & & & \multicolumn{2}{l}{$\begin{array}{l}\text { Nonmatch-to-sample } \\
(600 \mathrm{~s})\end{array}$} \\
\cline { 2 - 4 } Group & Phase 3 & Best & Intermediate & Worst & & Object & Location \\
\hline $\mathrm{N}$ & 522 & 94.2 & 89.6 & 81.7 & & 86.3 & 72.0 \\
$\mathrm{H}$ & 890 & 88.4 & 78.9 & 63.7 & & 80.5 & 59.3 \\
$\mathrm{TH} / \mathrm{TF}$ & 925 & 90.7 & 74.0 & 57.3 & & 70.0 & 56.7 \\
$\mathrm{PRh}$ & 944 & 82.5 & 72.0 & 50.5 & & 48.7 & 67.3 \\
\hline
\end{tabular}

Data are the averaged group performances during transverse patterning and nonmatch-to-sample tasks. Scores are expressed as trials-to-criterion for phase 3 and percentage of correct responses for all other measures.

all interactions were reliable, including the three-way group $\times$ task $\times$ delay interaction $\left(F_{\text {Huynh-Feldt }(9,39)}=2.17 ; p<0.04\right)$. Because delay was a significant interacting factor, additional comparisons were made at the longest delay of $10 \mathrm{~min}$. Comparing performance of the four groups on each task at this delay yielded a main effect of group $\left(F_{(3,13)}=6.57 ; p<0.01\right)$ and of task $\left(F_{(3,13)}=10.39 ; p<0.01\right)$ as well as a group $\times$ task interaction $\left(F_{(3,13)}=11.68 ; p<0.001\right)$. Post hoc (Tukey) comparisons for each task indicated that for DNMS, group PRh differed reliably from controls and from group $\mathrm{H}(p<0.001$ and $p<0.01$, respectively), but the comparison with group TH/TF did not reach significance $(p<0.09)$. For DNML, the pattern was reversed. Group PRh did not differ from controls $(p>0.05)$ on this task, whereas group $\mathrm{H}$ and group TH/TF did $(p<0.039$ and $p<0.057$, respectively). However, the difference between the lesioned groups on this task was not significant $(p>0.05$ in all cases).

\section{Discussion}

Damage to parahippocampal cortical areas TH and TF and to the PRh produced memory impairments that differed in severity and type. Damage to areas TH/TF had only a mild effect on the object recognition DNMS task, mostly at the longest delay, whereas the same cortical lesions severely affected performance on recognition for location (DNML). Conversely, damage to the PRh (areas 35 and 36) impaired performance on the DNMS but not on DNML. Both lesions impaired acquisition and performance of phase 3 of the transverse patterning problem, although the cortical damage did not impact acquisition of phases 1 and 2 or the transfer to a nonconfigural problem set. Thus, the results yielded a dissociation between damage to the two cortical regions and recognition memory for objects or places, but both regions contributed to acquisition and performance of transverse patterning. These results will be discussed in turn.

\section{Recognition memory}

The pattern of impairment after damage to the PRh and areas $\mathrm{TH} / \mathrm{TF}$ in the present study can clearly be related to their position in the ventral and dorsal visual pathway, respectively [for a review of these connections, see Lavenex and Amaral (2000) and Lavenex et al. (2002, 2004)] (Ungerleider and Mishkin, 1982; Blatt et al., 2003). These results agree with the well established role of the PRh for object memory (Meunier et al., 1993; Murray et al., 2000) and that of TH/TF for spatial memory in rats (Bucci et al., 2000; Liu and Bilkey, 2002), monkeys (Nemanic and Bachevalier, 2002; Málková and Mishkin, 2003), and humans (Aguirre et al., 1998; Bohbot et al., 1998). However, Nemanic et al. (2004) had already shown that damage to areas TH/TF impaired memory for objects at the longest delays. Furthermore, the present findings showed that damage to both cortical areas im- 
paired transverse patterning but not the transfer set, suggesting that it is not only the type of information (e.g., object vs spatial) but rather the cognitive demands of the task that will determine the degree to which one area will be required for object memory.

\section{Transverse patterning}

The new finding that damage to TH/TF impairs a nonspatial configural task, such as transverse patterning, is consistent with recent neuroimaging data in humans indicating activation of these cortical areas during recognition of familiar stimulus configurations (Duzel et al., 2003). The dissociation between impaired performance on transverse patterning and spared performance on the elemental transfer set, which differs by a single stimulus and is identical in setting and response requirements, cannot reflect differences in contextual or spatial processing as such, nor can it reflect differences in item-based learning or maintenance of working memory. Rather, the impairment could reflect the inability to form or process conjunctive, configural, or relational representations. For example, area TH/TF might play a role in dissociating different configurations (spatial or nonspatial) that can then lead to the appropriate response. Additionally, damage to this region might disrupt communication between area 46 in the dorsolateral prefrontal cortex and the medial temporal lobe, which may affect performance of transverse patterning (M. C. Alvarado, J. Bachevalier, M. Mishkin, and L. Málková, unpublished results) by affecting appropriate choice behavior with respect to items within a configuration.

With regard to the $\mathrm{PRh}$, the results from the transverse patterning task suggest that the role of the PRh is not simply one of object recognition memory. The poor performance on phase 3 after perirhinal lesions could be ameliorated by a change in the task solution, which entailed the addition of a new object. Because the difference between phase 3 and the transfer set is whether or not the task requires configural, relational, or conjunctive representations, the pattern of results suggests that the difficulty is in forming configural or relational representations. This view is supported by previous results in monkeys suggesting a role of the PRh in stimulus-stimulus associations (Murray et al., 1993) and by a study showing a role for the entorhinal cortex in relational representations (Buckmaster et al., 2004).

Another interpretation of the present findings is that the effects of perirhinal lesions on transverse patterning may be related to levels of stimulus ambiguity. It has been suggested that the PRh is important both for perception and memory, particularly when "feature ambiguity" characterizes the task (Bussey et al., 2003). In the transverse patterning task, the objects were perceptually distinct but had a high ambiguity with respect to reward, and the use of conjunctive representations permits to disambiguate the meaning of the individual stimuli and to guide correct behavior. Thus, a high level of reward ambiguity could affect performance after perirhinal lesions. Nevertheless, the same lesions had no effect on the transfer discriminations, which also had two problems that shared ambiguous stimuli, but could be solved on the basis of reward history because of the anchoring endpoints A and $\mathrm{X}$. In essence, our data suggest that the PRh contributes to the formation of conjunctive or configural representations. Because the objects comprising the transverse patterning and transfer sets were highly discriminable, our data do not comment on the proposed role of the PRh on perception (Buckley et al., 2001) or resolving feature ambiguity (Bussey et al., 2003), except to agree with the idea that complex discriminations of low-feature ambiguity did not require the $\mathrm{PRh}$ unless a specific mnemonic process is required to solve the task.

\section{Temporal cortical versus hippocampal damage}

We have recently shown (Alvarado and Bachevalier, 2005) that incomplete damage to the hippocampal formation produces a lesion-size-dependent impairment on transverse patterning $(\mathrm{Ta}-$ ble 7) as well as on recognition of locations. These results support the view that the hippocampal formation is at the apex of a hierarchy of cortical structures important in the processing and storage of conjunctive representations that allow performance of spatial and nonspatial configural/relational problems. That damage to areas $\mathrm{TH} / \mathrm{TF}$ or PRh also impairs transverse patterning could indicate that the flow of information into the hippocampus has been disrupted, or that storage mechanisms within each cortical region have been altered, or that each of these areas contributes to the processing of configural/relational information and so, when damaged, will produce an impairment. The question becomes are these three areas contributing equally to performance in this task, or can they be dissociated in some ways on the basis of information processing or storage? On one level, areas TH/TF and the $\mathrm{PRh}$ are processing different aspects of visual information that can be characterized as associations between object-place in the case of TH/TF or associations between object-object (or object identity) and between objects and their motivational significance (Liu et al., 2000) in the case of PRh. The role of the hippocampus, as several current views propose, is to bind this information together to form a complete representation of an event. However, the degree to which this encoding requires the hippocampus or can be solved by cortical regions alone might depend on task parameters. For example, the biconditional discrimination $(\mathrm{AB}+, \mathrm{CD}+, \mathrm{BC}-, \mathrm{AD}-)$ is a configural problem that can be solved by animals with fornix transection (Saunders and Weiskrantz, 1989) or hippocampal damage (Whishaw and Tomie, 1991). However, the monkeys with fornix damage were at chance on a performance test that assessed whether they had learned to respond to individual configurations, or whether they had learned that the presence of feature A determines that a response to $\mathrm{B}$ and not $\mathrm{D}$ is indicated (control animals had learned these relationships). In contrast, damage to the PRh impairs the biconditional discrimination (Buckley and Gaffan, 1998; Bussey et al., 2002), suggesting that, in the absence of a functional hippocampus, this region was able to support configural processing but not pattern separation, a process that seems essential for good performance on the task (cf. O'Reilly and Rudy, 2001). One could suggest that the normal animal acquires two levels of information in transverse patterning: the stimulus configurations themselves (perhaps as a perceptual unit), which might engage the $\mathrm{PRh}$, and information about the relationships among the items or a conjunctive representation that preserves the identities of the individual items and how to respond depending on their combination, which would engage or require the hippocampal formation. If this were the case, it should be possible to shift the balance of power between the PRh and the hippocampus depending on perceptual nature of the stimulus configurations and the demands of the task. As discussed earlier, we have demonstrated that parahippocampal areas $\mathrm{TH}$ and $\mathrm{TF}$ also play a role in configural tasks, but whether it takes the form of providing relational information to the hippocampus, constructing configural representations, storage, retrieval, or recognition of such representations has yet to be determined.

\section{Conclusions}

We have now shown that parahippocampal areas TH/TF, the $\mathrm{PRh}$, and the hippocampal formation contribute differently, but cooperatively, to memory for objects, place, and inter-item relationships (Nemanic et al., 2004; Alvarado and Bachevalier, 2005; present study). Although our results are consistent with a view of 
temporal lobe function that places the hippocampal formation at the apex of information processing, they also highlight the important individual computations provided by cortical areas within the flow of information that can, and most likely do, support normal memory performance.

\section{References}

Aggleton JP, Keen S, Warburton EC, Bussey TJ (1997) Extensive cytotoxic lesions involving both the rhinal cortices and area TE impair recognition but spare spatial alternation in the rat. Brain Res Bull 43:279-287.

Aggleton JP, Vann SD, Oswald CJ, Good M (2000) Identifying cortical inputs to the rat hippocampus that subserve allocentric spatial processes: a simple problem with a complex answer. Hippocampus 10:466-474.

Aguirre GK, Zarahn E, D’Esposito M (1998) Neural components of topographical representation. Proc Natl Acad Sci USA 95:839-846.

Alvarado MC, Bachevalier J (2003) Damage to perirhinal and parahippocampal TH/TF cortices impairs performance on transverse patterning. Soc Neurosci Abstr 29:324.3.

Alvarado MC, Bachevalier J (2005) Selective neurotoxic damage to the hippocampal formation impairs performance of the transverse patterning and location memory tasks in rhesus macaques. Hippocampus 15:118-131.

Alvarado MC, Rudy JW (1995a) Rats with damage to the hippocampal formation are impaired on the transverse-patterning problem but not on elemental discriminations. Behav Neurosci 109:204-211.

Alvarado MC, Rudy JW (1995b) A comparison of kainic acid plus colchicine and ibotenic acid-induced hippocampal formation damage on four configural tasks in rats. Behav Neurosci 109:1052-1062.

Alvarado MC, Wright AA, Bachevalier J (2002) Object and spatial relational memory in adult rhesus monkeys is impaired by neonatal lesions of the hippocampal formation but not the amygdaloid complex. Hippocampus 12:421-433.

Angeli SJ, Murray EA, Mishkin M (1993) Hippocampectomized monkeys can remember one place but not two. Neuropsychologia 31:1021-1030.

Astur R, Constable RT (2004) Hippocampal dampening during a relational memory task. Behav Neurosci 118:667-675.

Beason-Held LL, Rosene DL, Killiany RJ, Moss MB (1999) Hippocampal formation lesions produce memory impairment in the rhesus monkey. Hippocampus 9:562-574.

Blatt GJ, Pandya DN, Rosene DL (2003) Parcellation of cortical afferents to three distinct sectors in the parahippocampal gyrus of the rhesus monkey: an anatomical and neurophysiological study. J Comp Neurol 466:161-179.

Bohbot VD, Kalina M, Stepankova K, Spackova N, Petrides M, Nadel L (1998) Spatial memory deficits in patients with lesions to the right hippocampus and to the right parahippocampal cortex. Neuropsychologia 36:1217-1238.

Brown MW, Aggleton JP (2001) Recognition memory: what are the roles of the perirhinal cortex and hippocampus? Nat Rev Neurosci 2:51-61.

Bucci DJ, Phillips RG, Burwell RD (2000) Contributions of postrhinal and perirhinal cortex to contextual information processing. Behav Neurosci 114:882-894.

Bucci DJ, Saddoris MP, Burwell RD (2002) Contextual fear discrimination is impaired by damage to the postrhinal or perirhinal cortex. Behav Neurosci 116:479-488.

Buckley MJ, Gaffan D (1998) Perirhinal cortex ablation impairs configural learning and paired-associate learning equally. Neuropsychologia 36:535-546.

Buckley MJ, Booth MC, Rolls ET, Gaffan D (2001) Selective perceptual impairments after perirhinal cortex ablation. J Neurosci 21:9824-9836.

Buckmaster CA, Eichenbaum H, Amaral DG, Suzuki WA, Rapp PR (2004) Entorhinal cortex lesions disrupt the relational organization of memory in monkeys. J Neurosci 24:9811-9825.

Burwell RD, Shapiro ML, O’Malley MT, Eichenbaum H (1998) Positional firing properties of perirhinal cortex neurons. NeuroReport 9:3013-3018.

Burwell RD, Saddoris MP, Bucci DJ, Wiig KA (2004) Corticohippocampal contributions to spatial and contextual learning. J Neurosci 24:3826-3836.

Bussey TJ, Muir JL, Aggleton JP (1999) Functionally dissociating aspects of event memory: the effects of combined perirhinal and postrhinal cortex lesions on object and place memory in the rat. J Neurosci 19:495-502.

Bussey TJ, Saksida LM, Murray EA (2002) Perirhinal cortex resolves feature ambiguity in complex visual discriminations. Eur J Neurosci 15:365-374.
Bussey TJ, Saksida LM, Murray EA (2003) Impairments in visual discrimination after perirhinal cortex lesions: testing "declarative" vs. "perceptual-mnemonic" views of perirhinal cortex function. Eur J Neurosci 17:649-660.

Clark RE, Broadbent NJ, Zola SM, Squire LR (2002) Anterograde amnesia and temporally graded retrograde amnesia for a nonspatial memory task after lesions of hippocampus and subiculum. J Neurosci 22:4663-4669.

Davachi L, Wagner AD (2002) Hippocampal contributions to episodic encoding: insights from relational and item-based learning. J Neurophysiol 88:982-990.

Driscoll I, Hamilton DA, Petropoulos H, Yeo RA, Brooks WM, Baumgartner RN, Sutherland RJ (2003) The aging hippocampus: cognitive, biochemical and structural findings. Cereb Cortex 13:1344-1351.

Dusek JA, Eichenbaum H (1998) The hippocampus and transverse patterning guided by olfactory cues. Behav Neurosci 112:762-771.

Duzel E, Habib R, Rotte M, Guderian S, Tulving E, Heinze HJ (2003) Human hippocampal and parahippocampal activity during visual associative recognition memory for spatial and nonspatial stimulus configurations. J Neurosci 23:9439-9444.

Eacott MJ, Machin PE, Gaffan EA (2001) Elemental and configural visual discrimination learning following lesions to perirhinal cortex in the rat. Behav Brain Res 124:55-70.

Eichenbaum H (2001) The hippocampus and declarative memory: cognitive mechanisms and neural codes. Behav Brain Res 127:199-207.

Eichenbaum H, Mathews P, Cohen NJ (1989) Further studies of hippocampal representation during odor discrimination learning. Behav Neurosci 103:1207-1216.

Ennaceur A, Neave N, Aggleton JP (1996) Neurotoxic lesions of the perirhinal cortex do not mimic the behavioural effects of fornix transection in the rat. Behav Brain Res 80:9-25.

Gaffan D (1994) Dissociated effects of perirhinal cortex ablation, fornix transection and amygdalectomy: evidence for multiple memory systems in the primate temporal lobe. Exp Brain Res 99:411-422.

Gaffan D, Harrison S (1989) Place memory and scene memory: effects of fornix transection in the monkey. Exp Brain Res 74:202-212.

Hampton RR, Hampstead BM, Murray EA (2004) Selective hippocampal damage in rhesus monkeys impairs spatial memory in an open-field test. Hippocampus 14:808-818.

Hanlon FM, Weisend MP, Huang M, Lee RR, Moses SN, Paulson KM, Thoma RJ, Miller GA, Canive JM (2003) A non-invasive method for observing hippocampal function. NeuroReport 14:1957-1960.

Heckers S, Zalesak M, Weiss AP, Ditman T, Titone D (2004) Hippocampal activation during transitive inference in humans. Hippocampus 14:153-162.

Hodos W, Bobko P (1984) A weighted index of bilateral brain lesions. J Neurosci Methods 12:43-47.

Iaria G, Petrides M, Dagher A, Pike B, Bohbot VD (2003) Cognitive strategies dependent on the hippocampus and caudate nucleus in human navigation: variability and change with practice. J Neurosci 23:5945-5952.

Jarrard LE, Davidson TL, Bowring B (2004) Functional differentiation within the medial temporal lobe in the rat. Hippocampus 14:434-449.

Kohler S, Crane J, Milner B (2002) Differential contributions of the parahippocampal place area and the anterior hippocampus to human memory for scenes. Hippocampus 12:718-723.

Lavenex P, Amaral DG (2000) Hippocampal-neocortical interaction: a hierarchy of associativity. Hippocampus 10:420-430.

Lavenex P, Suzuki WA, Amaral DG (2002) Perirhinal and parahippocampal cortices of the macaque monkey: projections to the neocortex. J Comp Neurol 447:394-420.

Lavenex P, Suzuki WA, Amaral DG (2004) Perirhinal and parahippocampal cortices of the macaque monkey: Intrinsic projections and interconnections. J Comp Neurol 472:371-394.

Liu P, Bilkey DK (1998a) Perirhinal cortex contributions to performance in the Morris water maze. Behav Neurosci 112:304-315.

Liu P, Bilkey DK (1998b) Excitotoxic lesions centered on perirhinal cortex produce delay-dependent deficits in a test of spatial memory. Behav Neurosci 112:512-524.

Liu P, Bilkey DK (2002) The effects of NMDA lesions centered on the postrhinal cortex on spatial memory tasks in the rat. Behav Neurosci 116:860-873.

Liu Z, Murray EA, Richmond BJ (2000) Learning motivational significance 
of visual cues for reward schedules requires the rhinal cortex. Nat Neurosci 3:1307-1315.

Maguire EA, Frith CD, Burgess N, Donnett JG, O’Keefe J (1998) Knowing where things are parahippocampal involvement in encoding object locations in virtual large-scale space. J Cogn Neurosci 10:61-76.

Málková L, Mishkin M (2003) One-trial memory for object-place associations after separate lesions of hippocampus and posterior parahippocampal region in the monkey. J Neurosci 23:1956-1965.

Málková L, Mishkin M, Bachevalier J (1995) Long-term effects of selective neonatal temporal lobe lesions on learning and memory in monkeys. Behav Neurosci 109:212-226.

Manns JR, Squire LR (1999) Impaired recognition memory on the Doors and People Test after damage limited to the hippocampal region. Hippocampus 9:495-499.

Meunier M, Bachevalier J, Mishkin M, Murray EA (1993) Effects on visual recognition of combined and separate ablations of the entorhinal and perirhinal cortex in rhesus monkeys. J Neurosci 13:5418-5432.

Mishkin M, Vargha-Khadem F, Gadian DG (1998) Amnesia and the organization of the hippocampal system. Hippocampus 8:212-216.

Moran JP, Dalrymple-Alford JC (2003) Perirhinal cortex and anterior thalamic lesions: comparative effects on learning and memory. Behav Neurosci 117:1326-1341.

Murray EA, Gaffan D, Mishkin M (1993) Neural substrates of visual stimulus-stimulus association in rhesus monkeys. J Neurosci 13:4549-4561.

Murray EA, Baxter MG, Gaffan D (1998) Monkeys with rhinal cortex damage or neurotoxic hippocampal lesions are impaired on spatial scene learning and object reversals. Behav Neurosci 112:1291-1303.

Murray EA, Bussey TJ, Hampton RR, Saksida LM (2000) The parahippocampal region and object identification. Ann NY Acad Sci 911:166-174.

Nagahara AH, Otto T, Gallagher M (1995) Entorhinal-perirhinal lesions impair performance of rats on two versions of place learning in the Morris water maze. Behav Neurosci 109:3-9.

Nemanic S, Bachevalier J (2002) Role of the hippocampal formation, perirhinal cortex and areas TH/TF in spatial recognition memory in monkeys. Soc Neurosci Abstr 28:585.1.

Nemanic S, Alvarado MC, Bachevalier J (2004) The hippocampal/parahippocampal regions and recognition memory: insights from visual paired comparison versus object delayed nonmatching in monkeys. J Neurosci 24:2013-2026.

O’Reilly RC, Rudy JW (2001) Conjunctive representations in learning and memory: principles of cortical and hippocampal function. Psychol Rev 108:311-345.

Otto T, Wolf D, Walsh TJ (1997) Combined lesions of perirhinal and entorhinal cortex impair rats' performance in two versions of the spatially guided radial-arm maze. Neurobiol Learn Mem 68:21-31.

Parkinson JK, Murray EA, Mishkin M (1988) A selective mnemonic role for the hippocampus in monkeys: memory for the location of objects. J Neurosci 8:4159-4167.

Ploner CJ, Gaymard BM, Rivaud-Pechoux S, Baulac M, Clemenceau S, Samson S, Pierrot-Deseilligny C (2000) Lesions affecting the parahippocampal cortex yield spatial memory deficits in humans. Cereb Cortex 10:1211-1216.

Preston AR, Shrager Y, Dudukovic NM, Gabrieli JDE (2004) Hippocampal contribution to the novel use of relational information in declarative memory. Hippocampus 14:148-152.

Reed JM, Squire LR (1999) Impaired transverse patterning in human am- nesia is a special case of impaired memory for two-choice discrimination tasks. Behav Neurosci 113:3-9.

Rickard TC, Grafman J (1998) Losing their configural mind. Amnesic patients fail on transverse patterning. J Cogn Neurosci 10:509-524.

Ridley RM, Timothy CJ, Maclean CJ, Baker HF (1995) Conditional learning and memory impairments following neurotoxic lesion of the CA1 field of the hippocampus. Neuroscience 67:263-275.

Rondi-Reig L, Libbey M, Eichenbaum H, Tonegawa S (2001) CA1-specific $\mathrm{N}$-methyl-D-aspartate receptor knockout mice are deficient in solving a nonspatial transverse patterning task. Proc Natl Acad Sci USA 98:3543-3548.

Rudy JW, Sutherland RJ (1995) Configural association theory and the hippocampal formation: an appraisal and reconfiguration. Hippocampus 5:375-389.

Saunders RC, Weiskrantz L (1989) The effects of fornix transection and combined fornix transection, mammillary body lesions and hippocampal ablations on object-pair association memory in the rhesus monkey. Behav Brain Res 35:85-94.

Squire LR, Shimamura AP, Amaral DG (1989) Memory and the hippocampus. In: Neural models of plasticity: experimental and theoretical approaches (Byrne J, Berry W, eds), pp 208-239. New York: Academic.

Stark CE, Bayley PJ, Squire LR (2002) Recognition memory for single items and for associations is similarly impaired following damage to the hippocampal region. Learn Mem 9:238-242.

Sutherland RJ, Rudy JW (1989) Configural association theory: the role of the hippocampal formation in learning, memory, and amnesia. Psychobiology 17:129-144.

Suzuki W, Eichenbaum H (2000) The neurophysiology of memory. Ann NY Acad Sci 911:175-191.

Suzuki WA, Amaral DG (1994a) Perirhinal and parahippocampal cortices of the macaque monkey: cortical afferents. J Comp Neurol 350:497-533.

Suzuki WA, Amaral DG (1994b) Topographic organization of the reciprocal connections between the monkey entorhinal cortex and the perirhinal and parahippocampal cortices. J Neurosci 14:1856-1877.

Ungerleider LG, Mishkin M (1982) Two cortical visual systems. In: Analysis of visual behavior (Ingle DJ, Goodale MA, Mansfield RJW, eds), pp 549_ 586. Cambridge, MA: MIT.

Vann SD, Brown MW, Erichsen JT, Aggleton JP (2000) Fos imaging reveals differential patterns of hippocampal and parahippocampal subfield activation in rats in response to different spatial memory tests. J Neurosci 20:2711-2718.

von Bonin G, Bailey P (1947) The neocortex of Macaca mulatta. Urbana, IL: University of Illinois.

Whishaw IQ, Tomie JA (1991) Acquisition and retention by rats of simple conditional and configural tasks using tactile and olfactory cues: implications for hippocampal function. Behav Neurosci 105:787-797.

Wiig KA, Bilkey DK (1994) Perirhinal cortex lesions in rats disrupt performance in a spatial DNMS task. NeuroReport 5:1405-1408.

Wiig KA, Burwell RD (1998) Memory impairment on a delayed nonmatching-to-position task after lesions of the perirhinal cortex in the rat. Behav Neurosci 112:827-838.

Winters BD, Forwood SE, Cowell RA, Saksida LM, Bussey TJ (2004) Double dissociation between the effects of peri-postrhinal cortex and hippocampal lesions on tests of object recognition and spatial memory: heterogeneity of function within the temporal lobe. J Neurosci 24:5901-5908.

Wood ER, Dudchenko PA, Eichenbaum H (1999) The global record of memory in hippocampal neuronal activity. Nature 397:613-616.

Yonelinas AP (2002) The nature of recollection and familiarity: a review of 30 years of research. J Mem Lang 46:441-517. 